Check for updates

Cite this: Phys. Chem. Chem. Phys., 2020, 22, 8284

Received 8th March 2020

Accepted 3rd April 2020

DOI: 10.1039/d0cp01311k

rsc.li/pccp

\section{Spectroscopic characterisation of radical polyinterhalogen molecules $\dagger$}

\author{
Joe Gregory, ${ }^{* a}$ Jan R. R. Verlet (iD ${ }^{b}$ and James N. Bull (D) ${ }^{a}$
}

\begin{abstract}
Spectroscopic characterisations of the radical polyinterhalogen molecules $\mathrm{IF}_{2}$ and $\mathrm{I}_{2} \mathrm{~F}$ are reported using anion photoelectron spectroscopy. The corresponding parent anions, $\mathrm{IF}_{2}{ }^{-}$and $\mathrm{I}_{2} \mathrm{~F}^{-}$, are common products formed in hard $\mathrm{Ar}-\mathrm{CF}_{3}$ l plasmas and are relevant in the semiconductor manufacture industry. The $\mathrm{I}_{2} \mathrm{~F}^{-}$species, which is present as the $[\mathrm{I}-\mathrm{I}-\mathrm{F}]^{-}$isomer, is a "non-classical" polyinterhalogen.
\end{abstract}

The propensity for halide anions to combine and form polyhalogen anions, such as $\mathrm{I}_{3}{ }^{-}$, has been known for around 200 years. ${ }^{1}$ However, examples and spectroscopic characterisation of polyinterhalogen molecules, particularly open-shell species, have proven to be elusive. ${ }^{2}$ To date, most spectroscopic characterisations of polyinterhalogen anions are as crystallised solids or have been performed in matrix isolation with a counter cation. ${ }^{2-4}$ There are no known vibrationally-resolved spectroscopic determinations of radical (open-shell) polyinterhalogen molecules. On the other hand, closed-shell polyinterhalogen molecules such as $\mathrm{IF}_{3}, \mathrm{IF}_{5}, \mathrm{IF}_{7}$ and $\mathrm{I}_{2} \mathrm{~F}_{4}$ are relatively stable compounds. Polyinterhalogen anions and their corresponding radical neutrals are appealing targets for gas-phase spectroscopy due to being textbook examples for valence-shell electron pair repulsion (VSEPR) theory and the Rundle-Pimentel scheme for hypervalency. ${ }^{5,6}$ They are also desirable systems to benchmark high-level quantum chemical calculations due to challenges associated with describing heavy atoms. ${ }^{7,8}$

This paper reports a combined photoelectron spectroscopy and electronic structure theory study on the $\mathrm{IF}_{2}{ }^{-}, \mathrm{I}_{2} \mathrm{~F}^{-}, \mathrm{IF}_{2}$ and $\mathrm{I}_{2} \mathrm{~F}$ species. There have been several reports of synthesis, crystallography and spectroscopic characterisation of $\mathrm{IF}_{2}^{-}$ embedded in a solid state matrix, ${ }^{9,10}$ and computational studies on $\mathrm{IF}_{2}^{-}$and $\mathrm{I}_{2} \mathrm{~F}^{-}$and related species, ${ }^{7,10-14}$ however, a recent

\footnotetext{
${ }^{a}$ School of Chemistry, Norwich Research Park, University of East Anglia, Norwich NR4 7TJ, UK. E-mail: james.bull@uea.ac.uk

${ }^{b}$ Department of Chemistry, Durham University, South Road, Durham DH1 3LE, UK $\dagger$ Electronic supplementary information (ESI) available: Experimental methods, theoretical methods, calculated vertical excitation energies, further Franck-Condon simulations. See DOI: 10.1039/d0cp01311k
}

review by Riedel and co-workers ${ }^{2}$ noted "Thus far, .. $\left[\mathrm{I}_{2} \mathrm{~F}\right]^{-}$have not been detected experimentally." While this statement might be true for condensed phases, $\mathrm{I}_{2} \mathrm{~F}^{-}$appears to be a common product formed in hard $\mathrm{Ar}-\mathrm{CF}_{3} \mathrm{I}$ plasmas.

There are only a handful of examples of gas-phase spectroscopic studies on polyhalogen species, mostly targeting $\mathrm{I}_{3}{ }^{-}$. A series of pioneering investigations by Neumark and co-workers ${ }^{15-18}$ applied anion photoelectron spectroscopy with different laser sources to characterise vibronic properties of the radical neutral $\mathrm{I}_{3}$, and photodissociation dynamics of the parent anion. Several other studies have focussed on photodissociation dynamics. ${ }^{19-22}$ There have been two investigations on $\mathrm{I}_{2} \mathrm{Br}^{-}$probing the dissociation dynamics, with one of these studies providing a single-colour photoelectron spectrum at $267 \mathrm{~nm}^{23,24}$ In the present work, we have coupled a jet-cooled plasma discharge source with time-of-flight mass spectrometry and anion photoelectron spectroscopy. This strategy allows for generation and mass selection of $\mathrm{IF}_{2}{ }^{-}$and $\mathrm{I}_{2} \mathrm{~F}^{-}$, and determination of spectroscopic properties of the radical neutral $\mathrm{IF}_{2}$ and $\mathrm{I}_{2} \mathrm{~F}$ species.

Intriguingly, radical polyinterhalogen molecules may have a significant bearing in industrial plasma processes. In particular, in the present study we produced the $\mathrm{IF}_{2}{ }^{-}$and $\mathrm{I}_{2} \mathrm{~F}^{-}$species through plasmisation of an $\mathrm{Ar}^{-} \mathrm{CF}_{3} \mathrm{I}$ mixture; this mixture and process is relevant in the semiconductor manufacture industry. In this industry, dry-etching plasma processes utilise the reaction between silicon wafers, which are the substrate for semiconductor and microprocessors, and fluorine atoms and $\mathrm{CF}_{3}$ radicals to etch the substrate at specific locations on the wafer. ${ }^{25}$ Conventionally, these radical species are produced in a plasma consisting of an inert carrier gas seeded with $\mathrm{CF}_{4}$ or $\mathrm{C}_{3} \mathrm{~F}_{8}$. In recent years, there has been growing interest in the use of $\mathrm{CF}_{3} \mathrm{I}$ as an alternative to $\mathrm{CF}_{4}$ because the use of $\mathrm{CF}_{4}$ is restricted in many countries by the Montreal Protocol due to the molecule's high global warming potential (GWP) ${ }^{26,27}$ For example, even though $\mathrm{CF}_{3} \mathrm{I}$ is infrared active, $\mathrm{CF}_{3} \mathrm{I}$ has an atmospheric residence life of $\approx 1$ day and corresponding GWP $\approx 1 .{ }^{28,29}$ In contrast, $\mathrm{CF}_{4}$ has a residence life of $\approx 50000$ years and corresponding GWP $\approx 6000 .^{29,30}$ Furthermore, although iodine atoms formed through UV photodissociation of 
$\mathrm{CF}_{3} \mathrm{I}$ are exceptionally destructive towards stratospheric ozone, ${ }^{31}$ the short residence time of $\mathrm{CF}_{3} \mathrm{I}$ released at terrestrial altitudes means that these molecules do not reach the stratosphere and contribute to ozone destruction. Ultimately, modelling and tuning of the etching process allows maximisation of process efficiency and minimisation of unwanted by-products. Theoretical plasma models require a detailed qualitative and quantitative understanding of the rich ion-molecule and electron-molecule chemistry that occurs in dry-etching plasmas (particularly the chemistry associated with fluorine-containing radicals). ${ }^{32-36}$

\section{$\mathrm{IF}_{2}{ }^{-} \& \mathrm{IF}_{2}$}

Photoelectron spectra for $\mathrm{IF}_{2}{ }^{-}$are shown in Fig. 1, revealing a clear vibrational progression with spacing $600 \pm 50 \mathrm{~cm}^{-1}$. The adiabatic detachment energy (ADE), assigned as the lowest energy discernible detaching vibration in the $h \nu=4.13 \mathrm{eV}$ spectrum, is $\mathrm{ADE}=4.03 \pm 0.02 \mathrm{eV}$. The vertical detachment energy (VDE), determined as the most intense vibration in the $h \nu=4.66 \mathrm{eV}$ photoelectron spectrum, is $\mathrm{VDE}=4.23 \pm 0.04 \mathrm{eV}$. These ADE and VDE values are most consistent with the calculated values (Table 1) for the $[\mathrm{F}-\mathrm{I}-\mathrm{F}]^{-}$isomer shown in Fig. 2; there was no evidence for the $[\mathrm{F}-\mathrm{F}-\mathrm{I}]^{-}$isomer, which was calculated to lie $2.74 \mathrm{eV}\left(264 \mathrm{~kJ} \mathrm{~mol}^{-1}\right.$ ) higher in energy. Calculated ADE and VDE values for $[\mathrm{F}-\mathrm{I}-\mathrm{F}]^{-}$at the $\operatorname{CCSD}(\mathrm{T}) / /$ def2-TZVPD level of theory (Table 1 ) are both $\approx 4 \%$ larger than the experimental values (similar to the result for $\mathrm{I}^{-}$given in the ESI $\dagger$ ). Increasing the basis set to def2-QZVPD gave calculated values that were $\approx 6 \%$ larger than the experimental values (Table 1). The better agreement with the smaller basis set is presumably a fortuitous cancellation of errors with some fraction of this associated with heavy atom/relativistic effects.

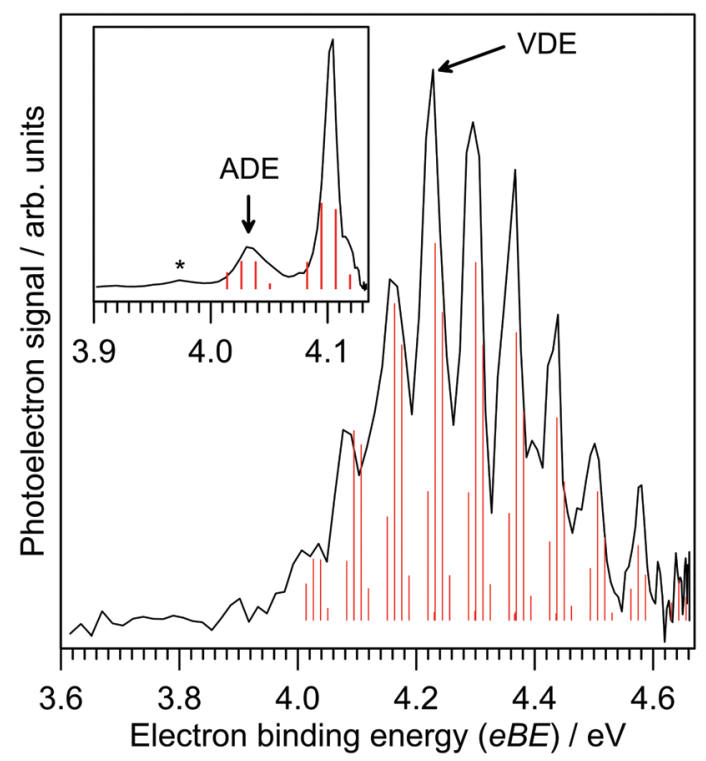

Fig. 1 Photoelectron spectra for $\mathrm{IF}_{2}{ }^{-}$at $h \nu=4.66 \mathrm{eV}$ and $4.13 \mathrm{eV}$ (inset) and Franck-Condon simulation (red sticks) of the $D_{0} \leftarrow S_{0}$ detaching transition for the $[\mathrm{F}-\mathrm{I}-\mathrm{F}]^{-}$isomer. Electron binding energy (eBE) and electron kinetic energy (eKE) are related by $\mathrm{eBE}=h \nu-\mathrm{eKE}$, where $h \nu$ is the photon energy.

Table 1 Experimental (subscript e) and calculated (subscript c) electron detachment energies for $\mathrm{IF}_{2}^{-}$and $\mathrm{I}_{2} \mathrm{~F}^{-}$. Calculations are at the $\operatorname{CCSD}(\mathrm{T}) /$ def2-TZVPD level of theory (CCSD(T)/def2-QZVPD in parentheses). Experimental uncertainties account for velocity-map imaging calibration using $\mathrm{I}^{-}$and pixel-to-energy conversion in image reconstruction

\begin{tabular}{lllll}
\hline & {$[\mathrm{F}-\mathrm{I}-\mathrm{F}]^{-}$} & {$[\mathrm{F}-\mathrm{F}-\mathrm{I}]^{-}$} & {$[\mathrm{I}-\mathrm{I}-\mathrm{F}]^{-}$} & {$[\mathrm{I}-\mathrm{F}-\mathrm{I}]^{-}$} \\
\hline $\mathrm{ADE}_{\mathrm{e}}$ & $4.03 \pm 0.02$ & - & $4.04 \pm 0.06$ & - \\
$\mathrm{VDE}_{\mathrm{e}}$ & $4.23 \pm 0.04$ & - & $4.23 \pm 0.04$ & - \\
$\mathrm{ADE}_{\mathrm{c}}$ & $4.14(4.15)$ & 3.17 & $4.22(4.28)$ & $3.19(3.38)$ \\
$\mathrm{VDE}_{\mathrm{c}}$ & $4.40(4.50)$ & 3.88 & $4.40(4.55)$ & $3.96(4.08)$
\end{tabular}

(a)

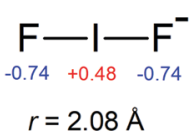

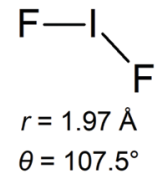

(b)

$$
\begin{array}{cc}
\mathrm{F}-\mathrm{F}-\mathrm{I}_{-0.74}^{-0.39+0.13} & \mathrm{~F}-\mathrm{F}-\mathrm{I} \\
r_{\mathrm{FF}}=2.00 \AA & r_{\mathrm{FF}}=3.05 \AA \\
r_{\mathrm{Fl}}=2.29 \AA & r_{\mathrm{Fl}}=1.91 \AA
\end{array}
$$

Fig. 2 Calculated equilibrium geometries at the CCSD(T)//def2-TZVPD level of theory for: (a) $[\mathrm{F}-\mathrm{I}-\mathrm{F}]^{-}$and $[\mathrm{F}-\mathrm{I}-\mathrm{F}]$, and (b) $[\mathrm{F}-\mathrm{F}-\mathrm{I}]^{-}$and $[\mathrm{F}-\mathrm{F}-\mathrm{I}]$. NBO charges (red and blue font) are given for the anions. The lowest energy isomer, $[\mathrm{F}-\mathrm{I}-\mathrm{F}]^{-}$has $D_{\infty \mathrm{h}}$ symmetry, and [F-I-F] has $C_{2 v}$ symmetry.

A Franck-Condon simulation of the photoelectron spectrum for the $[\mathrm{F}-\mathrm{I}-\mathrm{F}]^{-}$configuration is shown in Fig. 1 and has good agreement with the experimental spectrum. The simulation suggests that the vibrational progression is dominated by detaching transitions to the $\nu_{2}$ (asymmetric stretch) and $\nu_{3}$ (symmetric stretch) vibrations of the [F-I-F] radical neutral species; calculated frequencies suggest that these two vibrations are nearly degenerate - see Table 2 . We can therefore assign the experimental value of $\nu_{2} / \nu_{3}$ at $600 \pm 50 \mathrm{~cm}^{-1}$ for the $[\mathrm{F}-\mathrm{I}-\mathrm{F}]$ species. The small feature denoted by ${ }^{*}$ in the inset in Fig. 1 is probably a hot band from vibrationally-excited ions produced in the plasma (see ESI $\dagger$ ). The $\mathrm{ADE}$ assignment to the $0-0$ transition should be robust based on alignment of the VDE with the Franck-Condon simulation. It is worth noting that a FranckCondon simulation of the photoelectron spectrum for the $[\mathrm{F}-\mathrm{F}-\mathrm{I}]^{-}$isomer (see vibrational frequencies for $[\mathrm{F}-\mathrm{F}-\mathrm{I}]$ in Table 2) is inconsistent with the experimental spectra, lending support to the above isomer assignment.

Calculated vertical excitation energies for the $[\mathrm{F}-\mathrm{I}-\mathrm{F}]^{-}$isomer are given in Table S1 in the ESI. $\dagger$ These data show that although an excited state resonance is energetically accessible with a $h \nu=$ $4.66 \mathrm{eV}$ photon, oscillator strengths are zero and therefore the photoelectron spectra in Fig. 1 should be described by direct photodetachment to the ground electronic state of the neutral.

Table 2 Calculated harmonic vibrational frequencies for $\mathrm{IF}_{2}^{-}$and $\mathrm{IF}_{2}$ at the $\operatorname{CCSD}(T) / /$ def2-TZVPD level of theory in units of $\mathrm{cm}^{-1}$

\begin{tabular}{lllll}
\hline Mode & {$[\mathrm{F}-\mathrm{I}-\mathrm{F}]^{-}$} & {$[\mathrm{F}-\mathrm{I}-\mathrm{F}]$} & {$[\mathrm{F}-\mathrm{F}-\mathrm{I}]^{-}$} & {$[\mathrm{F}-\mathrm{F}-\mathrm{I}]$} \\
\hline$\nu_{1}$ & $193^{a}$ & $96^{a}$ & $137^{a}$ & $18^{a}$ \\
$\nu_{2}$ & $193^{a}$ & $547^{c}$ & $137^{a}$ & $18^{a}$ \\
$\nu_{3}$ & $401^{c}$ & $548^{b}$ & $230^{c}$ & $38^{b}$ \\
$\nu_{4}$ & $437^{b}$ & - & $247^{b}$ & $614^{c}$
\end{tabular}

${ }^{a}$ Bend. ${ }^{b}$ Symmetric stretch. ${ }^{c}$ Asymmetric stretch. [F-F-I] has $C_{\infty \mathrm{h}}$ symmetry. Note the symmetric $v s$. asymmetric stretch mode ordering. 
Calculated vertical excitation energies for neutral $[\mathrm{F}-\mathrm{I}-\mathrm{F}]$, i.e. electronic excited states of $[\mathrm{F}-\mathrm{I}-\mathrm{F}]$ at the $[\mathrm{F}-\mathrm{I}-\mathrm{F}]^{-}$equilibrium geometry, suggested that only the ground electronic state is accessible using the photon energies in Fig. 1, consistent with a single vibrational progression.

\section{$\mathrm{I}_{2} \mathrm{~F}^{-} \& \mathrm{I}_{2} \mathrm{~F}$}

Photoelectron spectra for $\mathrm{I}_{2} \mathrm{~F}^{-}$at three photon energies are shown in Fig. 3a, revealing two detachment bands. The lower binding energy band has $\mathrm{ADE}=4.04 \pm 0.06 \mathrm{eV}$ and $\mathrm{VDE}=$ $4.23 \pm 0.04 \mathrm{eV}$. There is no clear vibrational structure. The higher binding energy band has ADE2 $=4.60 \pm 0.04 \mathrm{eV}$ and VDE2 $=4.68 \pm$ $0.04 \mathrm{eV}$, and vibrational spacing of $550 \pm 100 \mathrm{~cm}^{-1}$.

The ADE and VDE parameters for the lower energy band are consistent with the calculated values for the $[\mathrm{I}-\mathrm{I}-\mathrm{F}]^{-}$isomer (Table 1), again with a small overestimation by theory. The two bands in Fig. 3a are thus assigned to detaching transitions to the ground and excited electronic states of the $[\mathrm{I}-\mathrm{I}-\mathrm{F}]$ radical neutral. Equilibrium geometries for the $\mathrm{I}_{2} \mathrm{~F}^{-}$and $\mathrm{I}_{2} \mathrm{~F}$ isomers are shown in Fig. 4; the $[\mathrm{I}-\mathrm{I}-\mathrm{F}]^{-}$isomer is more stable by $1.35 \mathrm{eV}\left(130 \mathrm{~kJ} \mathrm{~mol}^{-1}\right)$, consistent with it being the predominant isomer formed in the plasma. There was no evidence for the $[\mathrm{I}-\mathrm{F}-\mathrm{I}]^{-}$
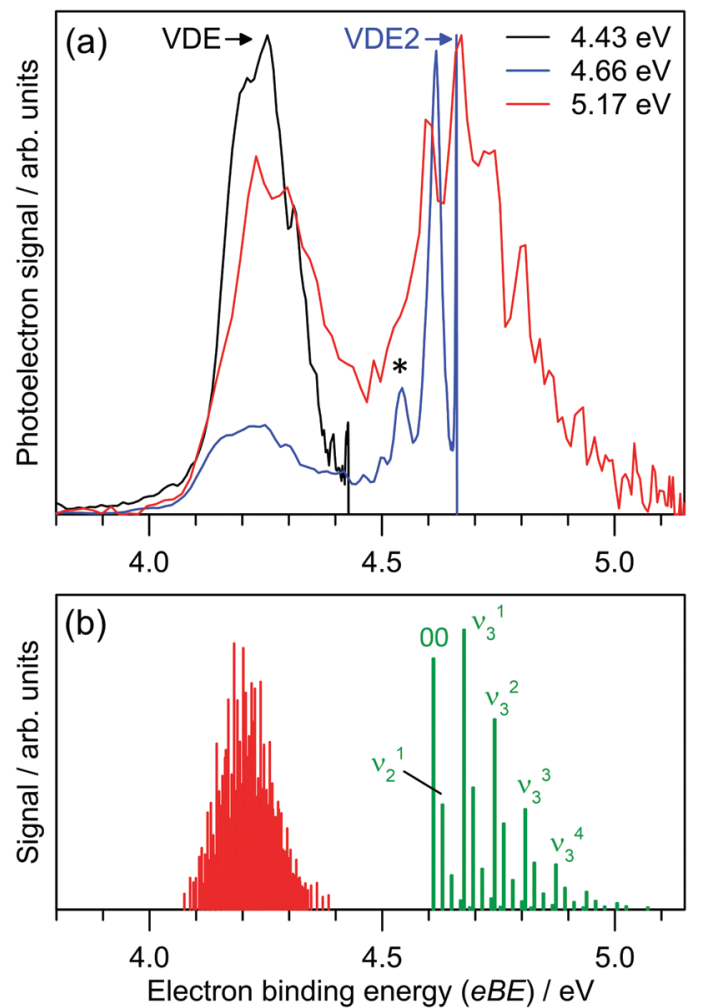

Fig. 3 (a) Photoelectron spectra for $\mathrm{I}_{2} \mathrm{~F}^{-}$at $h \nu=4.43,4.66$ and $5.17 \mathrm{eV}$. Electron binding energy (eBE) and electron kinetic energy (eKE) are related by $\mathrm{eBE}=h \nu-\mathrm{eKE}$, where $h \nu$ is the photon energy. (b) Franck-Condon simulation of direct photodetachment to the $D_{0}$ and $A_{1}$-symmetry neutral electronic states. The simulations suggest that the $D_{0} \leftarrow S_{0}$ detaching transition is dominated by low frequency modes and combination bands. See $\mathrm{ESI} \dagger$ for Franck-Condon simulations at higher temperatures which assign the feature denoted by * to a hot band. isomer when photoelectron spectra were recorded at photon energies below the ADE for the $[\mathrm{I}-\mathrm{I}-\mathrm{F}]^{-}$isomer. A FranckCondon simulation of the photoelectron spectrum to give the ground electronic state of the neutral (red in Fig. 3b) shows no clear vibrational structure, consistent with experimental spectrum. Calculated vibrational frequencies are given in Table 3.

The second, higher binding energy photodetachment band in Fig. 3a was assigned to direct photodetachment to the $\mathrm{A}_{1}$ state of the $[\mathrm{I}-\mathrm{I}-\mathrm{F}]$ species. Geometry optimisation of this state at the EOM-CCSD//def2-TZVPD level of theory produced a linear ( $C_{\infty \mathrm{h}}$ symmetry) structure with $r_{\mathrm{II}}=3.02 \AA$ and $r_{\mathrm{IF}}=1.96 \AA$. Using this structure, ADE2 was calculated at $4.79 \mathrm{eV}$ (term energy, $T_{\mathrm{e}}$, of $0.57 \mathrm{eV}$ which is close to the experimental value of $T_{\mathrm{e}}=0.56 \pm 0.08 \mathrm{eV}$ ), which is again $\approx 4 \%$ larger than experiment. Calculated vibrational frequencies for the $\mathrm{A}_{1}$ state are $\nu_{1}=109 \mathrm{~cm}^{-1}$ (bend), $\nu_{2}=157 \mathrm{~cm}^{-1}$ (symmetric stretch) and $\nu_{3}=530 \mathrm{~cm}^{-1}$ (asymmetric stretch). A Franck-Condon simulation of the photoelectron spectrum associated with formation of the $A_{1}$ state of the neutral is shown in green in Fig. $3 \mathrm{~b}$, and predicts that the vibrational structure is predominantly from the $\nu_{3}=530 \mathrm{~cm}^{-1}$ mode. The feature denoted by ${ }^{*}$ in Fig. $3 \mathrm{a}$ at $\mathrm{eBE}=4.56 \mathrm{eV}$ is assigned to hot band signal (see ESI $\dagger$ ).

Calculated vertical excitation energies for the $\mathrm{I}_{2} \mathrm{~F}^{-}$isomers are given in Table S1 in the ESI. $\dagger$ For the $[\mathrm{I}-\mathrm{I}-\mathrm{F}]^{-}$isomer, the first few electronic states have very low oscillator strengths and the photoelectron spectra for photon energies $<5 \mathrm{eV}$ should be dominated by direct photodetachment. There is, however, a bright $A_{1}$-symmetry resonance with a calculated vertical excitation energy in the 5.1-5.2 eV range (see ESI $\dagger$ ). Fortunately, the photoelectron spectra for both of these species are at lower binding energies and should not interfere with the spectra shown in Fig. 3. It is worth noting that the issue of bright excited state resonances in the detachment continuum is more serious for $\mathrm{I}_{3}{ }^{-}$(ref. 15-18) and larger polyinterhalogen anions due to an increased density of electronic states.

Polyinterhalogen molecules can be divided into two categories, classical and non-classical. ${ }^{3}$ The former is defined as containing an electropositive central atom surrounded by electronegative halogen atoms, e.g. $[\mathrm{F}-\mathrm{I}-\mathrm{F}]^{-}$. In contrast, for a non-classical polyinterhalogen molecule, the central halide is more electronegative than the coordinating dihalogen or interhalogen molecules, e.g. $\mathrm{Cl}\left(\mathrm{I}_{2}\right)_{4}{ }^{-}$in which four $\mathrm{I}_{2}$ molecules coordinate a $\mathrm{Cl}^{-} .3,37$ Interestingly, the $[\mathrm{I}-\mathrm{I}-\mathrm{F}]^{-}$species satisfies the nonclassical criterion, possessing covalent-like bond lengths and a (a)

$$
\begin{gathered}
\mathrm{I}-\mathrm{I}-\mathrm{F}_{-0.57+0.28 \quad-0.71}^{-} \\
r_{\mathrm{II}}=2.95 \AA \\
r_{\mathrm{IF}}=2.08 \AA
\end{gathered}
$$

(b)

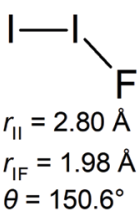

$$
\begin{array}{cc}
\underset{-0.21-0.58-0.21}{\mathrm{~F}-\mathrm{I}} & \\
r=2.31 \AA & r_{\mathrm{IF}}=3.10 \AA \\
& r_{\mathrm{FI}}=1.92 \AA \\
& \theta=118.9^{\circ}
\end{array}
$$

Fig. 4 Calculated equilibrium geometries at the CCSD(T)//def2-TZVPD level of theory for: (a) $[|-|-F]^{-}$and $[|-|-F]$, and (b) $[I-F-I]^{-}$and $[I-F-I]$. NBO charges (red and blue font) are given for the anions. The lowest energy isomer, $[\mathrm{I}-\mathrm{I}-\mathrm{F}]^{-}$has $C_{\infty \mathrm{h}}$ symmetry, and $[\mathrm{I}-\mathrm{I}-\mathrm{F}]$ has $C_{\mathrm{s}}$ symmetry. 
Table 3 Calculated harmonic vibrational frequencies for $\mathrm{I}_{2} \mathrm{~F}^{-}$and $\mathrm{I}_{2} \mathrm{~F}$ at the $\operatorname{CCSD}(\mathrm{T}) / /$ def2-TZVPD level of theory in units of $\mathrm{cm}^{-1}$

\begin{tabular}{lllll}
\hline Mode & {$[\mathrm{I}-\mathrm{I}-\mathrm{F}]^{-}$} & {$[\mathrm{I}-\mathrm{I}-\mathrm{F}]$} & {$[\mathrm{I}-\mathrm{F}-\mathrm{I}]^{-}$} & {$[\mathrm{I}-\mathrm{F}-\mathrm{I}]$} \\
\hline$\nu_{1}$ & $124^{a}$ & $102^{a}$ & $99^{a}$ & $20^{a}$ \\
$\nu_{2}$ & $124^{a}$ & $158^{b}$ & $99^{a}$ & $72^{b}$ \\
$\nu_{3}$ & $136^{b}$ & $502^{c}$ & $120^{b}$ & $606^{c}$ \\
$\nu_{4}$ & $402^{c}$ & - & $229^{c}$ & - \\
${ }^{a}$ Bend. ${ }^{b}$ Symmetric stretch. ${ }^{c}$ Asymmetric stretch. & \\
\hline
\end{tabular}

terminal $\mathrm{F}^{-}$coordinated to an $\mathrm{I}_{2}$ molecule (see NBO charges in Fig. 4). Similar arguments have been made about the $[\mathrm{I}-\mathrm{I}-\mathrm{Cl}]^{-}$ species in the solid state. ${ }^{3,38}$ Finally, it is worth noting that Mabbs et $a .^{23}$ reported a $267 \mathrm{~nm}$ photoelectron spectrum of $\mathrm{I}_{2} \mathrm{Br}^{-}$, which presumably exists as the $[\mathrm{I}-\mathrm{I}-\mathrm{Br}]^{-}$isomer and also is an example of a non-classical polyinterhalogen, however, their photoelectron spectrum showed no vibrational structure.

Our experiments suggest that $\mathrm{IF}_{2}{ }^{-}, \mathrm{I}_{2} \mathrm{~F}^{-}$and most likely the corresponding neutrals are amongst the major products formed in a hard $\mathrm{Ar}-\mathrm{CF}_{3} \mathrm{I}$ plasma. In the semiconductor manufacture industry, radical neutrals including $\mathrm{IF}_{2}$ and $\mathrm{I}_{2} \mathrm{~F}$ formed in the etching plasma may collide and react with etchant substrates. In this context, the bond dissociation energy (BDE) to produce a fluorine atom is related to etching efficiency - a lower BDE gives enhanced etching capacity. For the $[\mathrm{F}-\mathrm{I}-\mathrm{F}]$ and $[\mathrm{I}-\mathrm{I}-\mathrm{F}]$ isomers, BDEs for fluorine atoms were calculated at $1.74 \mathrm{eV}$ and $1.35 \mathrm{eV}$, respectively, using the $\operatorname{CCSD}(\mathrm{T}) / /$ def2-TZVPD level of theory. For comparison, the calculated $\mathrm{BDE}$ for a fluorine atom from the $\mathrm{CF}_{3}$ radical is $3.51 \mathrm{eV}$, which is substantially larger than that for the [F-I$\mathrm{F}]$ and $[\mathrm{I}-\mathrm{I}-\mathrm{F}]$ isomers and suggests that polyinterhalogen radicals formed in hard $\mathrm{Ar}-\mathrm{CF}_{3} \mathrm{I}$ plasmas are important etching species.

In summary, this paper has reported a combined photoelectron spectroscopy and electronic structure theory study on the $\mathrm{IF}_{2}{ }^{-}, \mathrm{IF}_{2}, \mathrm{IF}_{2}{ }^{-}$and $\mathrm{I}_{2} \mathrm{~F}$ species, determining the gas-phase structures and electron detachment parameters for the anions and vibrational structure of the neutrals. This determination provides the first vibrationally-resolved spectroscopic characterisation of isolated polyinterhalogen radicals. Whereas $\mathrm{IF}_{2}{ }^{-}$as the $[\mathrm{F}-\mathrm{I}-\mathrm{F}]^{-}$isomer is a classical polyinterhalogen molecule, $\mathrm{IF}_{2}{ }^{-}$as the $[\mathrm{I}-\mathrm{I}-\mathrm{F}]^{-}$isomer is a non-classical polyinterhalogen molecule. Theoretical modelling of these species has shown that the $\operatorname{CCSD}(\mathrm{T}) / /$ def2-TZVPD level of theory, on average, predicts $\mathrm{ADE}$ and VDE parameters to within $\approx 4 \%$ of experiment, however, this level of theory suffers from some degree of Pauling-point agreement. The $\mathrm{IF}_{2}$ and $\mathrm{I}_{2} \mathrm{~F}$ radicals may play an important role in plasma etching processes due to having low bond dissociation energies to give fluorine atoms.

\section{Conflicts of interest}

There are no conflicts to declare.

\section{Acknowledgements}

Funding was provided by a University of East Anglia start-up allowance (to JNB) and the European Research Council (Starting
Grant 306536 to JRRV). Electronic structure calculations were carried out on the High Performance Computing Cluster supported by the Research and Specialist Computing Support service at the University of East Anglia. Prof. Dr Sebastian Riedel, Freie Universität Berlin, is thanked for insightful discussions.

\section{Notes and references}

1 J. Pelletier and J. B. Caventou, Ann. Chim. Phys., 1819, 10, 142-176.

2 K. Sonnenberg, L. Mann, F. A. Redeker, B. Schmidt and S. Riedel, Angew. Chem., Int. Ed., 2020, 59, 5464-5493.

3 H. Haller and S. Riedel, Z. Anorg. Allg. Chem., 2014, 640, 1281-1291.

4 P. H. Svensson and L. Kloo, Chem. Rev., 2003, 103, 1649-1684.

5 R. J. Hach and R. E. Rundle, J. Am. Chem. Soc., 1951, 73, 4321-4324.

6 G. C. Pimente, J. Chem. Phys., 1951, 19, 446-448.

7 G. A. Landrum, N. Goldberg and R. Hoffmann, J. Chem. Soc., Dalton Trans., 1997, 3605-3613.

8 P. Pyykkö, Annu. Rev. Phys. Chem., 2012, 63, 45-64.

9 X. Zhang and K. Seppelt, Z. Anorg. Allg. Chem., 1997, 623, 491-500.

10 K. O. Christe, W. W. Wilson, G. W. Drake, M. A. Petrie and J. A. Boatz, J. Fluorine Chem., 1998, 88, 185-189.

11 Y. Ogawa, O. Takahashi and O. Kikuchi, THEOCHEM, 1998, 429, 187-196.

12 D. A. Dixon, D. J. Grant, K. O. Christe and K. A. Peterson, Inorg. Chem., 2008, 47, 5485-5494.

13 K. S. Thanthiriwatte, M. Vasiliu, D. A. Dixon and K. O. Christe, Inorg. Chem., 2012, 51, 10966-10982.

14 F. A. Redeker, A. Kropman, C. Müller, S. E. Zewge, H. Beckers, B. Paulus and S. Riedel, J. Fluorine Chem., 2018, 216, 81-88.

15 T. R. Taylor, K. R. Asmis, M. T. Zanni and D. M. Neumark, J. Chem. Phys., 1999, 110, 7607-7609.

16 M. T. Zanni, B. J. Greenblatt, A. V. Davis and D. M. Neumark, J. Chem. Phys., 1999, 111, 2991-3003.

17 H. Choi, R. T. Bise, A. A. Hoops and D. M. Neumark, J. Chem. Phys., 2000, 113, 2255.

18 H. Choi, T. R. Taylor, R. T. Bise, A. A. Hoops and D. M. Neumark, J. Chem. Phys., 2000, 113, 8608.

19 L. Zhu, K. Takahashi, M. Saeki, T. Tsukuda and T. Nagata, Chem. Phys. Lett., 2001, 350, 223-239.

20 A. A. Hoops, J. R. Gascooke, A. E. Faulhaber, K. E. Kautzman and D. M. Neumark, J. Chem. Phys., 2004, 120, 7901-7909.

21 R. Nakanishi, N. Saitou, T. Ohno, S. Kowashi, S. Yabushita and T. Nagata, J. Chem. Phys., 2007, 126, 204311.

22 J. A. Gibbard and R. E. Continetti, Faraday Discuss., 2019, 217, 203-219.

23 R. Mabbs, K. Pichugin, E. Surber and A. Sanov, J. Chem. Phys., 2004, 121, 265.

24 P. E. Crider, A. W. Harrison and D. M. Neumark, J. Chem. Phys., 2011, 134, 134306.

25 J. W. Coburn and H. F. Winters, J. Vac. Sci. Technol., 1979, 16, 391-403.

26 P. Forster, V. Ramaswamy, P. Artaxo, T. Berntsen, R. Betts, D. W. Fahey, J. Haywood, J. Lean, D. C. Lowe, G. Myhre, 
J. Nganga, R. Prinn, G. Raga, M. Schulz and R. Van Dorland, Changes in Atmospheric Constituents and in Radiative Forcing, in Climate Change 2007: The Physical Science Basis. Contribution of Working Group I to the Fourth Assessment Report of the Intergovernmental Panel on Climate Change, ed. S. Solomon, D. Qin, M. Manning, Z. Chen, M. Marquis, K. Averyt, M. Tignor and H. Miller, Cambridge University Press, Cambridge, United Kingdom, 2007, ch. 2, p. 141.

27 Ø. Hodnebrog, M. Etminan, J. S. Fuglestvedt, G. Marston, G. Myhre, C. J. Nielsen, K. P. Shine and T. J. Wallington, Rev. Geophys., 2013, 51, 300-378.

28 S. Solomon, J. B. Burkholder, A. R. Ravishankara and R. R. Garcia, J. Geophys. Res., 1994, 99, 20929.

29 A. K. Jain, B. P. Briegleb, K. Minschwaner and D. J. Wuebbles, J. Geophys. Res.: Atmos., 2000, 105, 20773-20790.

30 C. M. Roehl, D. Boglu, C. Brühl and G. K. Moortgat, Geophys. Res. Lett., 1995, 22, 815-818.
31 S. Solomon, R. R. Garcia and A. R. Ravishankara, J. Geophys. Res., 1994, 99, 20491.

32 L. G. Christophorou and J. K. Olthoff, J. Phys. Chem. Ref. Data, 2000, 29, 553-569.

33 J. N. Bull, M. Bart, C. Vallance and P. W. Harland, Phys. Rev. A: At., Mol., Opt. Phys., 2013, 88, 062710.

34 J. N. Bull, J. W. L. Lee and C. Vallance, Phys. Rev. A, 2017, 91, 022704.

35 G. Mensa-Bonsu, D. J. Tozer and J. R. R. Verlet, Phys. Chem. Chem. Phys., 2018, 21, 13977-13985.

36 H. Köckert, D. Heathcote, J. W. L. Lee, W. Zhou, V. Richardson and C. Vallance, Phys. Chem. Chem. Phys., 2019, 21, 14296-14305.

37 C. Walbaum, M. Richter, U. Sachs, I. Pantenburg, S. Riedel, A. Mudring and G. Meyer, Angew. Chem., Int. Ed., 2013, 125, 12965-12968.

38 Y.-Q. Wang, Z.-M. Wang, C.-S. Liao and C.-H. Yan, Acta Crystallogr., Sect. C: Cryst. Struct. Commun., 1999, 55, 1503-1506. 